\title{
Growth Inhibition of Human Leukemia HL-60 Cells by an Antisense Phosphodiester Oligonucleotide Encapsulated into Fusogenic Liposomes
}

\author{
Masuo Kondoh, ${ }^{a}$ Takahiro Matsuyama, ${ }^{b}$ Ryo Suzuki, ${ }^{c}$ Hiroyuki Mizuguchi, ${ }^{d}$ Tsuyoshi Nakanishi, ${ }^{c}$ \\ Shinsaku NaKagaWa, ${ }^{c}$ Yasuo Tsutsumi, ${ }^{c}$ Mahito Nakanishi, ${ }^{e}$ Masao Sato,${ }^{a}$ and Tadanori MaYumi ${ }^{*, c}$ \\ Faculty of Pharmaceutical Sciences, Tokushima Bunri University, "Yamashiro-cho,Tokushima, Tokushima 770-8514, \\ Japan, Tanabe Seiyaku Co., Ltd. Pharmaceutics Research Laboratory," Osaka 541-8505, Japan, Faculty of \\ Pharmaceutical Sciences, Osaka University, ${ }^{C}$ 1-6 Yamadaoka, Suita, Osaka 565-0871, Japan, National Institute of Health \\ Sciences, ${ }^{\prime}$ Tokyo 158, Japan, and Research Institute for Microbial Diseases, ${ }^{e}$ Osaka University, 3-1 Yamadaoka, Suita, \\ Osaka 565-0871, Japan. Received February 23, 2000; accepted May 1, 2000
}

We report here the antisense effect of phosphodiester oligodeoxynucleotide (D-ODN) using fusogenic liposomes (FL) as its carrier. FL has envelope proteins of the Sendai virus within its membrane and introduces its contents directly and efficiently into cytosol by means of the virus-cell fusion mechanism. Using antisense (AS) DODN 15-mer complementary to the c-myc proto-oncogene mRNA, including the translation initiation codon site, we analyzed the growth of HL-60 cells by $\left[{ }^{3} \mathrm{H}\right]$-thymidine uptake. AS-ODNs encapsulated in FL inhibited the growth by about $70 \%$ that of the control HL-60 cells at $2.48 \mu \mathrm{m}$. In contrast, sense and scramble D-ODNs encapsulated in FL showed no effect of the growth of HL-60 cells at the same concentration. Even at $50 \mu \mathrm{M}$, free form D-ODNs did not show any effect. These results suggest that FL is potentially a useful delivery vehicle for oligonucleotide-based therapeutics, and that D-ODN may be a likely candidate for oligodeoxynucleotides when an efficient delivery system is used.

Key words fusogenic liposome; Sendai virus; HL-60 cell; phosphodiester oligonucleotide

Antisense oligonucleotides (AS-ODNs) have been shown to be very efficient in the selective inhibition of gene expression." However, the therapeutic application of AS-ODNs is currently limited by their physiological properties such as low cellular uptake, instability, and lack of tissue specificity. Phosphodiester oligonucleotides (D-ODNs) have a low penetration rate through the cell membrane, and are susceptible to degradation by nucleases, their half-life in cytosol is estimated to be $15 \mathrm{~min}^{2)}$ To overcome these obstacles, modified ODNs, such as phosphorothioate (S) ODN and methylphosphonate (MP) ODN, have been produced. ${ }^{3)}$ Among these, SODN, in which a sulfur atom replaces an oxygen atom in the phosphotriester moiety of D-ODN, is the most popular modified ODN because of its low cost and ease of productivity. While S-ODNs have been shown to increase resistance against nuclease attacks and have higher lipophilicity, they are toxic at high concentrations because of their unspecific binding to endogenous proteins. ${ }^{4}$ Other modified ODNs are also problematic for various reasons such as low productivity, high cost and low affinity to the target sequence. Therefore, the application of modified antisense ODN is limited.

Considering these obstacles, D-ODN should again be applied to antisense therapy through an adequate carrier. DODN shows the highest affinity to the target sequence among modified ODNs, as well as low toxicity to cells. Moreover, D-ODN introduced directly into the cytosol is delivered into the nucleus, which is where antisense effects mainly occur. ${ }^{5)}$ However, problems with low cellular uptake of D-ODN and their poor stability due to degradation by nucleases needs to be solved. In general, as D-ODN are taken up by pinocytosis or endocytosis, a large amount of D-ODNs is needed to show an antisense effect because of the lower delivery of D-ODN into cytosol ${ }^{6,7)}$ Although complexes of AS-ODN with cationic liposomes ${ }^{8,9)}$ and other modified liposomes ${ }^{10-12)}$ have been shown to enhance intracellular delivery, the delivery of ASODN into cytosol is not very efficient, as cellular uptake oc- curs through the endocytosis pathway. Cationic liposomes also exhibit cytotoxicity. ${ }^{13,14)}$ The direct introduction of DODN into cytosol, which defends against an attack by the lysosomal enzyme, with a safe and efficient carrier would be ideal for use in oligonucleotide-based therapeutics.

Previously, we developed the fusogenic liposome (FL) which introduces genes and proteins in vitro and in vivo much more efficiently than the cationic liposomes. ${ }^{14-17)} \mathrm{FL}$ has a virus envelope protein on its surface and it promptly fuses with the cell membrane in a receptor-dependent manner, similiar to that in the native virus particle. Consequently, FL introduces its contents directly into the cytoplasm.

In this study, we examined the antisense effect of D-ODN targeting the c-myc proto-oncogene in human premyeloytic leukemia cell line HL-60 cells using FL as a carrier in vitro.

\section{MATERIALS AND METHODS}

Egg phosphatidylcholine (PC) and L- $\alpha$-dimyristoryl phosphatidic acid (PA) were obtained from Nippon Oil and Fats (Tokyo, Japan). Cholesterol (Chol) was obtained from Sigma (St. Louis, MO, U.S.A.). Polycarbonate membrane (pore size $0.4 \mu \mathrm{m}$. Nuclepore) was obtained from Coaster (Cambridge, MA, U.S.A.). Fragment A of the diphtheria toxin (DTA) was prepared as described previously. ${ }^{18)}$ ODNs were purchased from Vector Research (Suita, Osaka, Japan). The sequence is as follows. Antisense: $5^{\prime}$-AACGTTGAGGGGCAT-3', Sense: 5'-ATGCCCCTCAACGTT-3' and Scramble: 5'-GTACACATGGGGAGT- $3^{\prime} \cdot{ }^{19)}$ The Sendai virus was prepared as described by Nakanishi et al. ${ }^{20)}$

Liposome Preparation Unilamellar liposomes were prepared by the reverse-phase evaporation method ${ }^{21)}$ with some modifications (PC:PA:Chol=5:4:1, molar rate) using $46 \mu \mathrm{mol}$ of lipid. They were sized by extrusion through a $0.4 \mu \mathrm{m}$ polycarbonate membrane and were separated from unencapusulated oligonucleotides by ultra-centrifugation, re- 
sulting in simple liposomes containing oligonucleotides. Then, they were incubated with the Sendai virus, in which genomic RNA was inactivated in advance by ultraviolet light irradiation $\left(2000 \mathrm{~J} / \mathrm{m}^{2}\right)$, at $37^{\circ} \mathrm{C}$ for $2 \mathrm{~h}$ with shaking. Fusogenic liposomes were purified by stepwise sucrose gradient centrifugation $(30-50 \%)(24000 \mathrm{rev} / \mathrm{min}, 2 \mathrm{~h})$ to remove the free Sendai virus. The concentration of fusogenic liposomes was determined by optical density at $540 \mathrm{~nm}$. The quantity of oligonucleotides encapsulated in fusogenic liposomes was determined by means of a fluorometric assay using 3,5-diaminobenzoic acid as described previously. ${ }^{14)}$ The concentration of oligonucleotide of the fusogenic liposome suspension at OD540 of 1.0 was $0.492 \mu \mathrm{m}$.

Cell Culture The HL-60 myeloid leukemic cells were purchased from ATCC and cultured in RPMI 1640 supplemented with $10 \%$ heat-inactived fetal calf serum (FCS) at $37^{\circ} \mathrm{C}$

Fusion Efficiency of Fusogenic Liposomes against HL60 Cells The fusion efficiency of FL was assessed as follows. $1 \times 10^{4} \mathrm{HL}-60$ cells seeded on a 96 -well plate were incubated with $50 \mu \mathrm{l}$ of FL containing DTA or empty FL at $37^{\circ} \mathrm{C}$. After $24 \mathrm{~h}$ in culture, the viability of the cells was evaluated by the colorimetric-3-(4,5-dimethylthiazol-2-yl)2,5-diphenyltetrazolium bromide (MTT) assay. ${ }^{22)}$ The viability was estimated as the $\%$ of untreated cells.

Effects of c-myc Antisense Oligonucleotide on Proliferation of HL-60 Cells HL-60 cells $\left(5 \times 10^{4}\right.$ cells/well) were cultured in RPMI1640 containing 10\% FCS with various concentrations of D-ODN or FL containing D-ODN for $24 \mathrm{~h}$. Then, the cells were pulse-labeled with $\left[{ }^{3} \mathrm{H}\right]$-thymidine $(0.5 \mu \mathrm{Ci})$ for $2 \mathrm{~h}$ and the $\left[{ }^{3} \mathrm{H}\right]$ count incorporated into the cells was determined. The growth inhibition of HL-60 cells was estimated as the \% of untreated cells. Data are expressed as means \pm S.D. for the three experiments.

\section{RESULTS}

Previously we reported that one of the functions of FL was as a carrier of plasmid DNA and proteins. ${ }^{14-17)}$ In this report we examined the antisense effect of D-ODN, complementary to the initiation codon of $\mathrm{c}$-myc mRNA, when it was encapsulated into FL using HL-60 myeloid leukemia cells which overexpress c-myc protein.

We reported that FL fuses with various cells, except for human primary lymphocytes. ${ }^{15,16)}$ First we examined whether FL can fuse with HL-60 cells and deliver their contents into the cytoplasm. DTA was used as a marker protein to analyze FL-cell fusion. DTA cannot enter the cell itself, but if it enters the cytoplasm, it strongly inhibits protein synthesis. ${ }^{23)}$ Figure 1 shows that empty FL with an OD540 of 0.5 did not kill the cells, while FL containing DTA with an OD540 of over 0.01 killed more than $85 \%$ of the cells. This result indicates that FL fuses very efficiently with HL-60 myeloid leukemic cells.

Next we examined the antisense effect of D-ODN encapsulated in FL on the proliferation of HL- 60 cells in comparison with free ODN. Free AS D-ODN exhibited 30\% inhibition of DNA synthesis in the control at $10 \mu \mathrm{M}$, but there was no significant difference in comparing antisense, sense and scramble ODN (Fig. 2A). In contrast, AS D-ODN encapsulated into $\mathrm{FL}$ exhibited $40 \%$ inhibition at $0.27 \mu \mathrm{M}(\mathrm{OD} 540=$ $0.53)$ and $80 \%$ inhibition at $2.46 \mu \mathrm{M}$ (OD540=5) (Fig. 2B). Sense and scramble D-ODN encapsulated into FL exhibited growth inhibition as well as void FL. This data suggested that AS-ODN encapsulated in FL showed the antisense effect in a sequence specific manner. Cationic liposome, which is

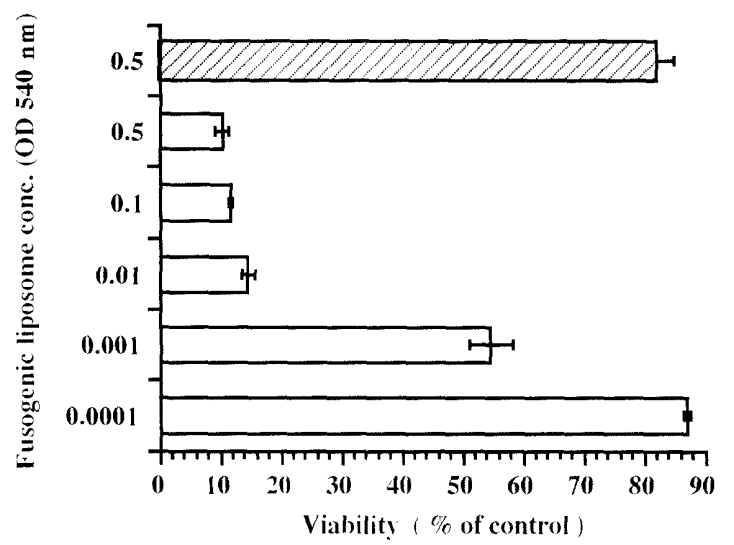

Fig. 1. Fusion Efficiency of Fusogenic Liposomes against HL-60 Cells

HL-60 cells were incubated with the indicated OD540 of DTA-FL (open bars) or empty-FL (slashed bars) at $37^{\circ} \mathrm{C}$ for $30 \mathrm{~min}$. After $24 \mathrm{~h}$ in culture, the viability was determined by MTT assay. Data are expressed as mean \pm S.D. for the three experiments.
A

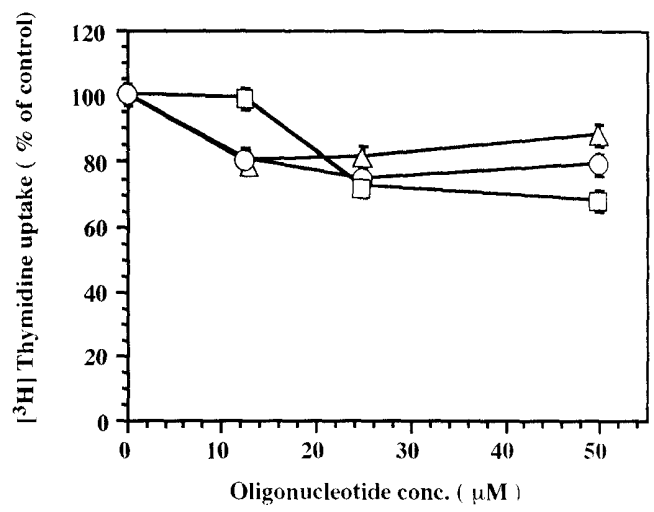

B

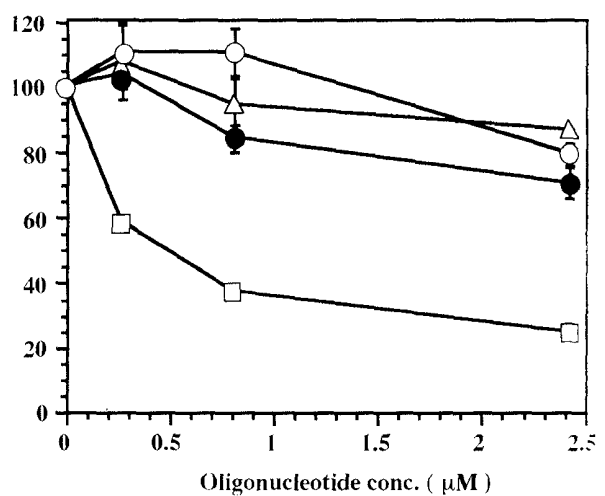

Fig. 2. The Effect of c-myc Antisense Oligonucleotides on the Proliferation of HL-60 Cells

HL-60 cells were treated with free form D-ODN (A) or D-ODN encapsulated in FL (B). Twenty-four hours later, the cells were pulse-labeled with $\left.{ }^{3} \mathrm{H}\right]$-thymidine for $2 \mathrm{~h}$ and the $\left[{ }^{3} \mathrm{H}\right]$ quantity incorporated into cells was determined. Data are expressed as the mean \pm S.D. for four experiments. (A) antisense oligonucleotides (open squares); sense (open circles); scramble (open triangles). (B) antisense oligonucleotides (open squares); sense (open circles); scramble (open triangles); empty (closed circles). 
the most common carrier of plasmid DNA and ODN, was toxic at high concentrations, ${ }^{13,14)}$ and it is important to develop a safe delivery system. Although FL with an OD540 above 5 exhibited slight toxicity, void FL was not toxic on HL-60 cells at the effective dose $(\mathrm{OD} 540=0.53$; ODN $=$ $0.27 \mu \mathrm{M}$ ) (Fig. 2B). This result indicates that FL is a safe and efficient carrier.

\section{DISCUSSION}

This study shows that D-ODN can be an oligonucleotide for antisense-based therapy when FL is used as a carrier. DODN is a potent ODN for antisense therapeutics due to its nontoxicity and high affinity to the target sequence. However, antisense-based therapy using D-ODN has limitations due to its low cellular uptake and low stability. Few investigations have reported that D-ODN exhibited an antisense effect, and in these studies liposomes or immunoliposomes were used as its carrier. ${ }^{19,24,25)} \mathrm{FL}$ is superior to other carriers in terms of its ability to introduce DNA and protein into cells. ${ }^{14)}$ By using FL, the disadvantages of D-ODN low cellular uptake and low stability are overcome, as D-ODN is efficiently delivered into the cytoplasm and avoids lysosomal enzyme damage. As a result of the direct and efficient introduction of D-ODN into cytosol by FL, specific antisense effects are observed in this study.

It has been reported that S-ODN inhibits the expression of target proteins not only in an antisense sequence specific manner but also in a non-specific manner. ${ }^{4,26,27)}$ Moreover, a recent report demonstrated that a c-myc AS-ODN containing a contiguous four-guanosine (4G) sequence inhibited the proliferation of smooth muscle cells (SMC cells) by a nonantisense mechanism. ${ }^{28)}$ In this study, we used D-ODN containing a contiguous G4 sequence as an antisense and scramble ODN. Growth inhibition of HL-60 cells was not obsereved when FL containing scramble ODN was used, while FL containing antisense ODN suppressed its growth. It is likely that D-ODN has no or few side effects. In conclusion, these results suggest that D-ODN introduced directly into cytosol is beneficial for antisense-based therapy.

\section{REFERENCES}

1) Scanlon K. J., Ohata Y., Ishida H., Kijima H., Ohkawa T., Kaminski A., Tsai J., Horng G., Kashani-sabet M., FASEB J., 9, 1288-1296 (1995).
2) Fisher T. L., Terhorst T., Cao X., Wagner R. W., Nucleic Acids Res, 21, 3857-3865 (1993).

3) Engilisch U., Gauss D. H., Angew. Chem. Int. Ed. Engl, 30, 613-722 (1991).

4) Krieg A. M., Stein C. A., Antisense Res. Dev., 5, 241 (1995).

5) Leonetti J. P., Mechti N., Deglos G., Gagnor C., Lebleu B., Proc. Natl. Acad. Sci. U.S.A., 88, 2702-2706 (1991).

6) Loke S. L., Stein C. A., Leonetti J. P., Proc. Natl. Acad. Sci. U.S.A., 86, $3474-3478$ (1989).

7) Wu-pong S., Weiss T. L., Hunt A., Antisense Res. Dev., 4, 155-163 (1994).

8) Chiang M.-Y., Chan H., Zounes M. A., Freier S. M., Lima W. F., Bennett C. F., J. Biol. Chem., 266, $18162-18171$ (1991).

9) Bennett C. F., Chiang M. Y., Chan H., Shoemaker J. E., Miralabelli C. K., Mol. Pharmacol., 41, 1023 -1033 (1992).

10) Thierry A. R., Dritschilo A., Nucleic Acids Res., 20, 5691-5698 (1992).

11) Ropert C., Malvy C., Couvreur P., Pharm. Res., 10, 1427-1433 (1993).

12) Zelphati O., Zon G., Leserman L., Antisense Res. Dev., 3, 323-338 (1993).

13) Woude I. V., Visser H. W., Beest M. B. A., Wagenaar A., Ruiters M. H., Egberts J. B. F. N., Hoekstra D., Biochim. Biophys. Acta, 1240, $34-40(1995)$.

14) Mizuguchi H., Nakagawa T., Nakanishi M., Imazu S., Nakagawa S., Mayumi T., Biochem. Biophys. Res. Commun., 218, 402-407 (1996).

15) Nakanishi M., Ashihara K., Senda T., Kondo T., Kato K., Mayumi T., In Trends and Future Perspectives in Peptide and Protein Drug Delivery, Lee VHL, Hashida M., Mizushima Y. (eds). (Harwood Academic Publishers: The Netherlands) pp. 337--349 (1995).

16) Mizuguchi H., Nakanishi M., Nakanishi T., Nakagawa T., Nakagawa S., Mayumi T., Br. J. Cancer, 73, 472-476 (1996).

17) Mizuguchi H., Nakanishi T., Nakanishi M., Nakagawa T., Nakagawa S., Mayumi T., Cancer Lett., 100, 63-69 (1996).

18) Uchida T., Yamaizumi M., Miyake Y., Okada Y., J. Cell Biol., 80, 1020 (1979).

19) Loke S. L., Stein C., Zhang X., Avigan M., Cohen J., Nekers L. M., Curr. Top. Microbiol. Immunol., 141, 282--289 (1988).

20) Nakanishi M., Uchida T., Sugawa H., Ishiura M., Okada Y., Exp. Cell Res., 159, 399-409 (1985).

21) Szoka F., Papahadjopoulos D., Proc. Natl. Acad. Sci. U.S.A., 75, 4194-4198 (1978).

22) Mosmman T., J. Immunol. Methods., 65, 55-63 (1983).

23) Yamaizumi M., Mekada E., Uchida T., Okada Y., Cell, 15, 245-250 (1978).

24) Leonetti J. P., Machy P., Deglos G., Lebleu B., Leserman L., Proc. Natl. Acad. Sci. U.S.A., 87, 2448-2451 (1990).

25) Capaccioli S., Pasquale G. D., Mini E., Mazzei T., Quattrone A., Biochem. Biophys. Res. Commun., 197, 818-825 (1993).

26) Wagner R. W., Nature (London), 372, 333-335 (1994).

27) Wagner R. W., Nat. Med., 1, $1116-1121$ (1995).

28) Buegess T. L., Fisher E. F., Ross S. L., Brendy J. Y., Qian Y. X., Bayewitch L. A., Cohen A. M., Herrera C. J., Hu S. S. F., Kramer T. B., Lott F. D., Maritn F. H., Pierce G. F., Simonet L., Farrell C. L., Proc. Natl. Acad. Sci. U.S.A., 92, 4051-4055 (1995). 